\title{
Lost in Transition: A Systematic Review of Neonatal Electroencephalography in the Delivery Room - Are We Forgetting an Important Biomarker for Newborn Brain Health?
}

\author{
Daragh Finn ${ }^{1,2}$, Eugene M. Dempsey ${ }^{1,2}$ and Geraldine B. Boylan ${ }^{1,2 *}$ \\ ${ }^{1}$ Department of Paediatrics and Child Health, University College Cork, Cork, Ireland, ${ }^{2}$ rrish Centre for Fetal and Neonatal \\ Translational Research, University College Cork, Cork, Ireland
}

OPEN ACCESS

Edited by:

Maximo Vento,

Universitat de València, Spain

Reviewed by:

Fernando Cabañas,

Foundation for Biomedical Research of La Paz University

Hospital, Spain

MaryAnn Volpe,

Tufts University School of

Medicine, United States

Robert Galinsky,

University of Auckland,

New Zealand

${ }^{*}$ Correspondence:

Geraldine B. Boylan

g.boylan@ucc.ie

Specialty section:

This article was submitted to

Neonatology,

a section of the journal

Frontiers in Pediatrics

Received: 19 April 2017

Accepted: 24 July 2017

Published: 10 August 2017

Citation:

Finn D, Dempsey EM and Boylan GB (2017) Lost in Transition: A

Systematic Review of Neonatal

Electroencephalography in the

Delivery Room-Are We Forgetting

an Important Biomarker for

Newborn Brain Health?

Front. Pediatr. 5:173.

doi: 10.3389/fped.2017.00173
Background: Electroencephalography (EEG) monitoring is routine in neonatal intensive care units (NICUs) for detection of seizures, neurological monitoring of infants following perinatal asphyxia, and increasingly, following preterm delivery. EEG monitoring is not routinely commenced in the delivery room (DR).

Objectives: To determine the feasibility of recording neonatal EEG in the DR, and to assess its usefulness as a marker of neurological well-being during immediate newborn transition.

Methods: We performed a systematic stepwise search of PubMed using the following terms: infant, newborns, neonate, DR, afterbirth, transition, and EEG. Only human studies describing EEG monitoring in the first 15 min following delivery were included. Infants of all gestational ages were included.

Results: Two original studies were identified that described EEG monitoring of newborn infants within the DR. Both prospective observational studies used amplitude-integrated EEG (aEEG) monitoring and found it feasible in infants > 34 weeks' gestation; however, technical challenges made it difficult to obtain continuous reliable data. Different EEG patterns were identified in uncompromised newborns and those requiring resuscitation.

Conclusion: EEG monitoring is possible in the DR and may provide an objective baseline measure of neurological function. Further feasibility studies are required to overcome technical challenges in the DR, but these challenges are not insurmountable with modern technology.

Keywords: newborn, electroencephalography, neuro-monitoring, delivery room, hypoxic-ischemic encephalopathy, prematurity

\section{INTRODUCTION}

Electroencephalography (EEG) has become a routine component of neurological monitoring in the neonatal intensive care unit (NICU) $(1,2)$. It has well-documented benefits in monitoring newborn infants with perinatal asphyxia (3-6) and seizures (7-13) and in predicting long-term outcome (14-21). Five to ten percent of newborn infants require some measure of stabilization in 
the delivery room (DR) (22). The majority of infants who require complex stabilization are either extremely premature or have sustained birth asphyxia. In recent decades, the survival rates for both preterm and asphyxiated infants have improved, but neurodevelopmental morbidity has not decreased in corresponding order $(23,24)$. An increased focus on the early identification and prevention of brain injury in newborn infants is now a major focus of newborn care in the setting of the NICU. However, neurological monitoring is not routine during newborn stabilizations in the DR, nor is it recommended in recent international guidelines $(25,26)$. First, we will discuss the current methods for assessing brain health in the DR, and then we outline our rationale for considering EEG as a very useful biomarker of brain health in the DR. Table 1 summaries the different assessment tools discussed.

\section{CURRENT METHODS FOR ASSESSING BRAIN HEALTH IN THE DR}

At present, neonatal stabilization teams rely on clinical parameters to assess a newborn infant's neurological status during immediate newborn transition. Assessments of muscle tone and reflex irritability are incorporated into the Apgar score, which is routinely assigned to infants after 1 and $5 \min (27,28)$. However, Apgar scores are subjective and inter-rater variability is high (29). Neonatal objective hemodynamic monitoring with reliable, continuous, non-invasive measurements of physiological parameters such as heart rate and pre-ductal oxygen saturations (with pulse oximetry) is now routine in the DR (29-32). However, neonatal stabilization teams do not have objective information available about neurological function during resuscitation. The availability of accurate and objective baseline neurological information may help guide resuscitation and plan appropriate early interventions for neonates that may not have tolerated the stresses of labor so well.

Studies that have previously sought to introduce neurological monitoring into the DR initially focused on cerebral blood flow using Doppler measurements of cerebral or carotid arteries (33-38). More recently, studies have concentrated on near infrared spectroscopy (NIRS), which provides non-invasive monitoring of cerebral tissue oxygenation in the DR (39-46). Guidelines for the use of NIRS monitoring and EEG in NICUs overlap, and it is advised that they should be used simultaneously (6).

\section{RATIONALE FOR PROPOSING EEG AS A BIOMARKER OF NEWBORN BRAIN HEALTH IN THE DR}

Electroencephalography is not a new technique, but its application in neonatology in the past has been hampered by a lack of appropriate technology for recording and analysis. This has changed dramatically in the last decade, and there are now high quality digital amplifiers available that can record excellent EEG signals even in very noisy environments. The time is now right to reexplore the use of EEG as a valuable biomarker of neurological function in the DR; an environment where previously, it was just not possible.

The signal measured by the EEG is of the order of microvolts and represents a direct measure of postsynaptic neuronal activity in the cortex. Research has shown that the EEG of fetal sheep can be recorded during labor (47-49). Thaler and colleagues performed intrapartum EEG on fourteen women with uncomplicated pregnancies (50), and a clinical trial of EEG monitoring during labor is currently underway (https://clinicaltrials.gov/ct2/ show/NCT03013569). During normal labor, the fetus is exposed to brief but repeated episodes of hypoxia, which are balanced by the fetus's striking ability to adapt to these episodes (51). Fetal EEG monitoring in both human and animal studies during labor has shown that these episodes are associated with rapid EEG amplitude reduction and also with fast amplitude recovery as soon as the uterine contraction ends $(48,52)$. The EEG is exquisitely sensitive to any impairment in oxygen delivery to the brain. A reduction in oxygen leads to an immediate suppression of synaptic transmission with a reduction (often complete

TABLE 1 | Current and possible future tools for assessing neonatal brain health in the delivery room (DR).

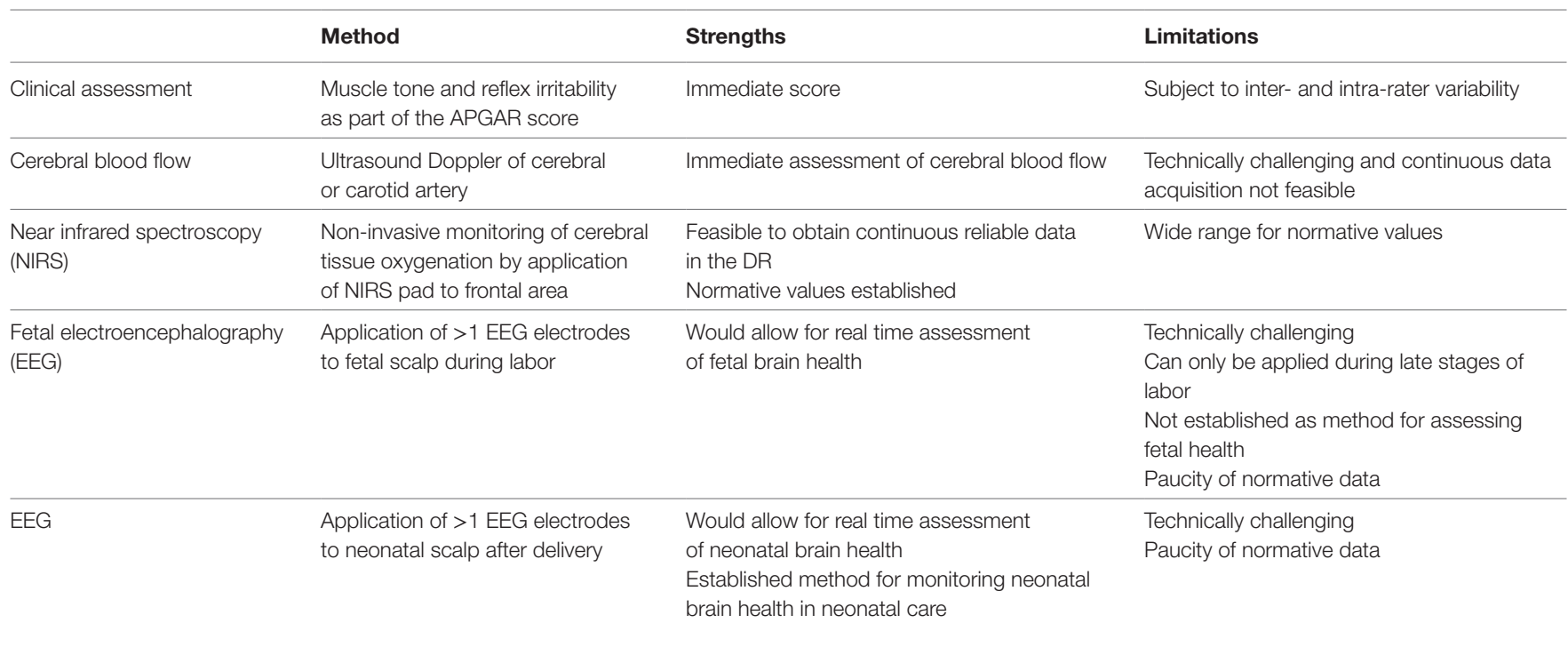


suppression) in EEG amplitude $(48,53)$. This adaptive response, believed to be mediated by multiple inhibitory neuromodulators including adenosine, to hypoxia may be protective by decreasing energy consumed by the generation of synaptic potentials (54). If cerebral hypoxia is sustained, however, EEG amplitudes remain severely reduced and membrane failure will eventually occur accompanied by energy depletion and cell damage (52). Thus, sustained changes in the EEG signal a risk of impending brain injury.

In neonates with hypoxic-ischemic encephalopathy (HIE), an EEG showing sustained suppression for hours after birth has long been associated with a very poor outcome $(5,15,55,56)$. Neonatal EEG monitoring is recommended for all infants with moderate and severe HIE, and neonatal teams are now familiar with its application in NICUs. Fetal EEG monitoring has clear benefits for the early recognition of HI injury but requires considerable research before it is adopted as a routine tool for fetal surveillance. Immediate EEG acquisition in the DR on the other hand is much more feasible and may quickly identify those neonates that have not tolerated labor and delivery very well, which will be seen as disrupted patterning on the EEG.

An early EEG in the DR of an infant requiring resuscitation will indicate if EEG activity is present or not or if EEG activity returns following this stabilization process. As we know that EEG activity should recover immediately following restoration of oxygen delivery to the brain, if EEG activity does not return immediately post resuscitation or activity is severely disrupted, this indicates that the infant is at risk of hypoxic-ischemic brain injury. This could provide a clear indication for immediate passive cooling prior to transfer to the NICU. This early indication of cerebral function is very important as Thoresen et al. have shown that infants cooled within $3 \mathrm{~h}$ of birth have better neurodevelopmental outcomes when compared to infants whose cooling commenced between 3 and $6 \mathrm{~h}$ (57). Further improvements in outcome are highly likely to arise from earlier improved identification of affected infants that would allow earlier initiation of treatment after resuscitation.

Therefore, early EEG monitoring could provide neonatal stabilization teams with valuable, much needed, information about the neurological status of the newborn infant immediately after birth. Thus, we set out to assess whether any studies had already attempted to measure the human EEG in the DR by conducting a systematic review of available literature. We also aimed to establish the feasibility of EEG monitoring in the DR, and determine whether valuable information has been acquired from its application thus far.

\section{METHODS}

\section{Search Strategy}

We performed a systematic stepwise search of PubMed as per the Preferred Reporting Items for Systematic Reviews and MetaAnalyses (58). Articles up to and including February 2017 were included. Studies had to involve EEG monitoring in the DR. Search terms included the following: infant, newborns, neonate, DR, afterbirth, transition, and EEG. Only human studies were included, and this was incorporated into the initial search. Additional published reports identified in review articles or referenced in articles screened were also included. Publication bias was not assessed.

\section{Study Selection}

Articles identified by our search strategy were screened for inclusion by one author (DF). Titles and abstracts were initially screened. Articles had to pertain to EEG monitoring immediately after birth. Studies that focused on infants post birth asphyxiation or infants who had intracranial pathology were excluded as the subjects were, by nature, recruited post-delivery and not relevant to our search. Studies that specified a time frame for initial EEG monitoring outside of the first $15 \mathrm{~min}$ of life, or initial recruitment outside of the DR were also excluded. Where uncertainty remained regarding eligibility for inclusion the full text was reviewed. Studies that were not available in English were excluded.

\section{RESULTS}

Our initial search identified 215 articles (see Appendix 1 in Supplementary Material). After assessment of these articles, two original studies were identified that described EEG monitoring of the newborn infant within the DR (Figure 1). One study also contributed to a review article identified by our search, which was excluded from our study to avoid duplication (59). Table 2 summarizes the two studies identified.

Pichler et al. performed a prospective observational study of infants born by elective cesarean section over 34 weeks gestational age (60). Infants at lower gestational ages were excluded due to concerns about their small head size, and the feasibility in applying EEG leads and NIRS to a small surface area. Four gold electrodes (two frontal and two parietal) were applied with contact gel, along with an NIRS pad to the left forehead, and overlying elastic bandages for support. Amplitude-integrated EEG (aEEG), a rectified, filtered, and compressed form of EEG, was acquired and stored. Overall, they found that aEEG monitoring of the newborn infant in the DR is feasible, but it is difficult to obtain continuous reliable data. Of a total number of 63 infants, 17 (27\%) were excluded due to unreliable data. Of the remaining 46 infants, no data were recorded prior to $3 \mathrm{~min}$ of delivery, $25 \%$ had data available at $3 \mathrm{~min}$, and just over $50 \%$ were available at $5 \mathrm{~min}$. aEEG data were analyzed for mean minimum and mean maximum voltages every minute, and then correlated with cerebral oxygenation, heart rate and pre-ductal oxygen saturations. Findings were then compared between infants who were uncompromised at birth $(n=31)$ and infants who required neonatal resuscitation $(n=16)$.

Different cerebral activity patterns were identified between uncompromised newborns and those requiring resuscitation. They reported that infants in the uncompromised transition group started with initially high voltages on aEEG, followed by a significant decrease to baseline voltages at 4-5 min. In contrast, infants in the group requiring respiratory support did not show this pattern. However, there were no significant differences between minimum and maximum voltages when the two groups 


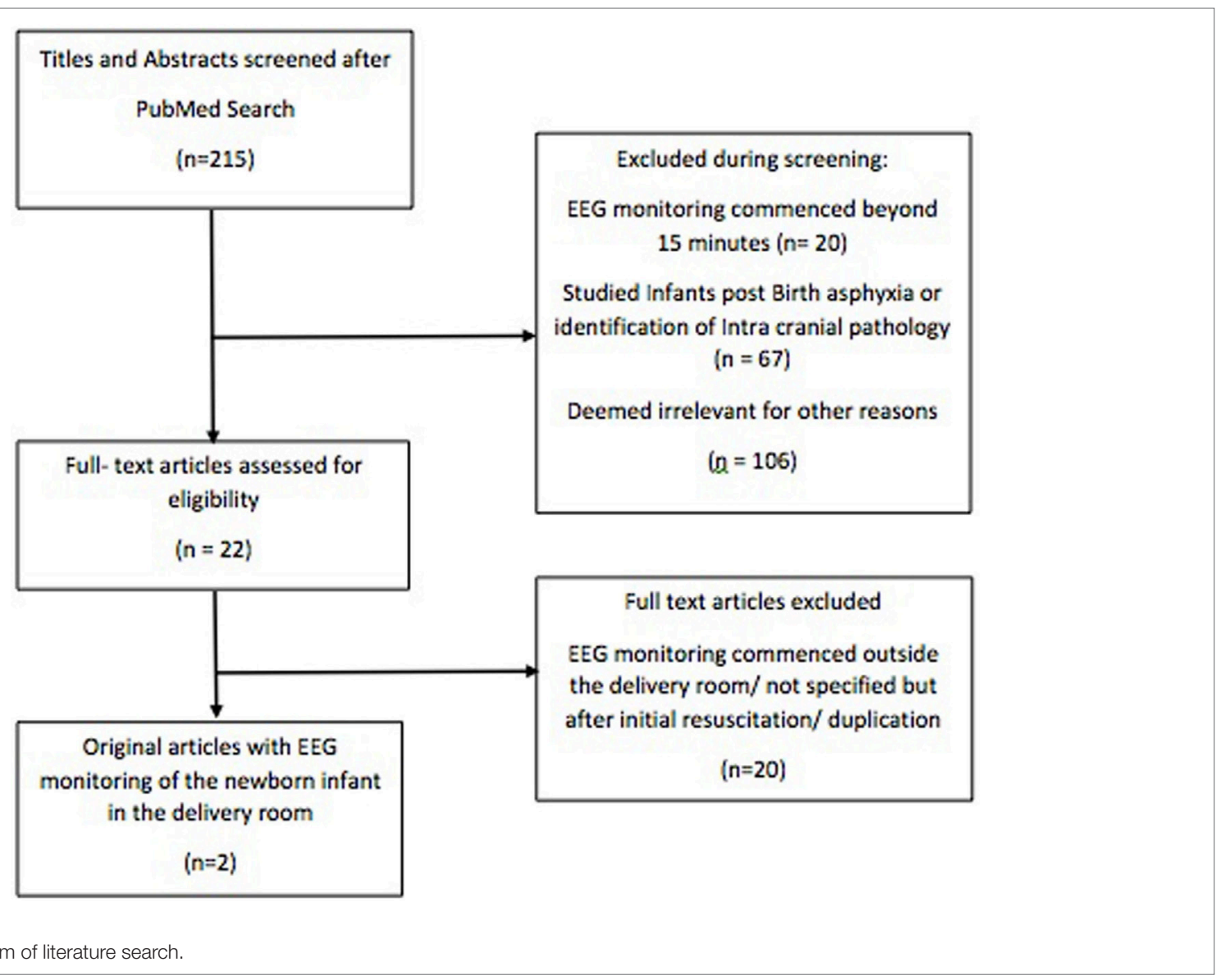

TABLE 2 | Summary of electroencephalography (EEG) studies in the delivery room.

\begin{tabular}{|c|c|c|c|c|c|}
\hline Reference & Neonates & $\begin{array}{l}\text { Number } \\
\text { recruited and } \\
\text { monitored }\end{array}$ & Design & $\begin{array}{l}\text { Number included } \\
\text { in analysis }\end{array}$ & Observation \\
\hline Pichler et al. $(42,60)$ & >34 weeks & 46 & $\begin{array}{l}\text { Observational } \\
\text { Amplitude-integrated EEG (aEEG) } \\
\text { analysed for minimum and maximum } \\
\text { voltages } \\
\text { Near infrared spectroscopy (NIRS) }\end{array}$ & $\begin{array}{l}N=46 \\
31 \text { uncompromised } \\
15 \text { required } \\
\text { respiratory support }\end{array}$ & $\begin{array}{l}\text { No significant differences between minimum } \\
\text { and maximum voltages when the } 2 \text { groups are } \\
\text { compared } \\
\text { Uncompromised infants had higher } V \text { max in minute } \\
3 \text { and } 4 \text { compared with minute } 10\end{array}$ \\
\hline Tamussino et al. (61) & Term & 244 & $\begin{array}{l}\text { Observational } \\
\text { aEEG analysed for minimum and } \\
\text { maximum voltages } \\
\text { Infants with initial low voltages which } \\
\text { normalized were compared to infants } \\
\text { with normal voltages throughout } \\
\text { NIRS }\end{array}$ & $\begin{array}{l}N=59 \\
9 \text { met inclusion } \\
\text { criteria } \\
50 \text { control studies }\end{array}$ & $\begin{array}{l}\text { Neonates with initially low cerebral activity during } \\
\text { immediate transition after birth displayed lower } \\
\text { cerebral saturations ( }<10 \text { th percentile) on NIRS, but } \\
\text { increased cerebral oxygen extraction (cFTOE >90th } \\
\text { percentile) }\end{array}$ \\
\hline
\end{tabular}

were compared, which the authors attribute to low numbers in the respiratory support group.

Tamussino et al. recorded simultaneous aEEG and NIRS in 244 term neonates during the first 15 min after delivery (61). Similar to the study of Pichler et al., aEEG data were analyzed for mean minimum and mean maximum voltages every minute, and then correlated with cerebral oxygenation, heart rate, and pre-ductal oxygen saturations. Neonates with initial low voltages, which normalized during transition, were compared to neonates with normal aEEG values throughout the monitoring period. Nine neonates had low initial aEEG voltages and were compared to 50 neonates with normal aEEG voltages throughout. Therefore, of 244 infants recruited, 59 aEEG recordings were included in the analysis. Neonates with initially low cerebral activity during immediate transition after birth displayed lower cerebral saturations $(<10$ th percentile) on NIRS, but increased cerebral oxygen 
extraction ( $\mathrm{cFTOE}>90$ th percentile). The authors concluded that neuro-monitoring with aEEG and NIRS might provide useful information on the neonates' condition during immediate transition.

\section{DISCUSSION}

Neonatal mortality has decreased significantly in recent decades (24). As more infants survive following preterm delivery and birth asphyxia, achieving the best possible neurological outcomes for survivors is paramount. Whilst EEG has an essential role within the NICU in newborn neurological monitoring following birth asphyxia, and in monitoring preterm infants, it is not routinely initiated in the DR, and at present has no role during newborn stabilizations. We set out to determine if first it was feasible to perform newborn EEG in the DR, second to assess what information it provides about newborn brain activity in the immediate postnatal period and most importantly, to determine if this early objective information about brain activity would be useful. We found two studies that had performed aEEG during the first $15 \mathrm{~min}$ of birth. They found aEEG to be feasible in infants $>34$ weeks, but technically difficult to obtain continuous reliable data. Patterns of brain activity differed between infants that required newborn stabilization measures and infants that transitioned from the fetal to neonatal period without the need for medical intervention (60). Also, newborn infants with initially low cerebral activity during immediate transition after birth displayed lower cerebral saturations and increased cerebral oxygen extraction, compared with normal voltages throughout (61). The authors proposed a number of possible explanations for the differences between groups. They postulated that apnea, respiratory distress, and bradycardia in the immediate newborn may result in a lower cardiac output and resultant lower brain activity in compromised infants (60). For uncompromised infants who had initially high levels of activity, they suggested that catecholamine release may be responsible (62).

The brain is the most vulnerable organ in newborn infants. A non-invasive, continuous method to measure cerebral activity (EEG) is already available but it has not transitioned to the DR. Initial research focused on cerebral blood flow measurements but they were found to be technically difficult and did not provide continuous data (59). NIRS has shown great promise in providing continuous data on cerebral tissue oxygenation values. It utilizes the transparency of biological tissue to light in the near infrared spectrum to measure cerebral tissue oxygenation (63). A number of studies have examined cerebral oxygenation using NIRS in the DR (59), and recently, normative values for infants not requiring resuscitation have been published (42).

As the importance of the early instigation of neuroprotective strategies for term newborns with perinatal asphyxia has become evident, EEG monitoring (usually aEEG) has become more common in NICUs $(1,7)$. In contrast to cerebral blood flow and NIRS, EEG has well documented applications in the clinical management of newborn infants. It is the gold standard method for the accurate detection of all neonatal seizures in term and preterm infants $(6,9)$. It has well-proven efficacy in predicting outcomes following perinatal asphyxia, based on patterns of poor background activity and the timing of sleep wake cycling reestablishment $(14,15,64,65)$. Prediction of outcome following preterm delivery is more complicated, but investigations are ongoing (20). Several studies have shown that early background EEG suppression correlates with severity of periventricular hemorrhage (66-68). Also, continuous displays of inter-burst interval duration, which differs with gestational age, may become a useful prognostic measure in preterm infants in the near future $(69,70)$.

Despite its importance in monitoring the newborn brain in the NICU, EEG monitoring in the DR is currently not recommended. Stabilization of newborn infants in the DR, including infants with perinatal asphyxia, occurs without any objective measure of brain activity, and we found only two studies that have assessed the feasibility of obtaining a newborn EEG recording in the DR. Both studies used the aEEG trend and both found it possible to obtain aEEG tracings within 3 min in some cases, but obtaining continuous reliable data was generally difficult (60). Within these limitations the authors describe different patterns in brain activity for infants that required respiratory support and infants that transitioned independently. Also, aEEG was correlated with different cerebral oxygenation patterns. These findings are important as they pave the way for future studies.

Both studies analyzed brain activity by interrogating the aEEG mean minimum and mean maximum voltages. However, the aEEG trend alone is a high level summary measure of the EEG with poor time resolution due to compression in the aEEG algorithm, and it does not display the second by second activity of the brain; as a result, it is not optimal for application in the DR. Digital aEEG machines obtain one or two channels of EEG signal, which is then amplified and passed through an asymmetric bandpass filter that strongly attenuates activity less than $2 \mathrm{~Hz}$ and more than $15 \mathrm{~Hz}$, to minimize artifacts. Additional processing includes semilogarithmic amplitude compression, rectification, and time compression (13). Heavy signal processing used in the aEEG algorithm eliminates much of the detail (e.g. frequency band content) available in the EEG, and many clinically important features are lost. Furthermore, there is no clear definition for aEEG, and most EEG machines implement different versions of the aEEG algorithm (71). The mean and maximum of the aEEG voltage need to be plotted and displayed for a number of minutes before any assessment of the overall baseline EEG activity can be made. In addition, it is well known that interpretation of the background aEEG pattern can be problematic due to baseline drift and other artifacts $(72,73)$. This is not optimal for DR EEG recording when real-time second by second information would be advantageous. For example, a recording of approximately $30 \mathrm{~s}$ duration alone using standard EEG would be enough to establish the presence of continuous EEG activity in a term newborn. This information would be hugely beneficial in the DR to help guide resuscitation and to determine the need for immediate passive cooling. Thoresen et al. coined the phrase "time is brain" in relation to the timing of cooling for neuroprotection (57), and we strongly believe that EEG in the DR could help identify those infants who would benefit most from early neuroprotective strategies.

Whether EEG could play a role in prognostication for infants requiring $\mathrm{TH}$ in the immediate newborn period is less clear. From clinical and preclinical studies, we know that recovery of 
EEG activity during the first $24 \mathrm{~h}$ after hypoxia ischemia, after a period of prolonged (several hours) suppression, can be associated with normal outcome $(74,75)$, and little to no histological injury (76). However, we now know that infants with even mild HIE can have cognitive delays at 5 years (14). The prolonged suppression is an actively mediated response, at least partially mediated by neurosteroids such as pregnanes and adenosine, which are upregulated for hours after the insult $(77,78)$. Previous papers that reported normal outcomes in infants with an initial flat EEG trace that recovered quickly and had normal outcome were limited by small numbers and follow-up continued until 2 years of age (75). The authors even admit this themselves as they say that "a normal score in the early years cannot preclude later neurological, perceptual-motor, or cognitive abnormalities" (75). Therefore, we continue to recommend multichannel continuous EEG monitoring for such infants for the duration of TH.

Electroencephalography in its raw format (not a modified aEEG) can be assessed both qualitatively and quantitatively. Qualitative EEG analysis is mainly used for clinical purposes. It is based on visual interpretation of the EEG signal and describes background features such as amplitude, frequency, and continuity of the EEG, symmetry, synchrony, and sleep-wake cycling. Quantitative EEG analysis is a method predominantly used in research and includes time and frequency domain analysis. Neither study identified in our review analyzed the EEG in its raw format, either for qualitative or quantitative purposes.

However, we still have a way to go before EEG monitoring is routine in the DR. Signal interpretation is difficult, but huge advances have already been made in quantitative analysis of the neonatal EEG and we now have algorithms that can accurately grade the EEG in term and preterm newborns $(70,79-84)$. The feasibility of EEG recording is constantly improving and newer amplifiers with high common mode rejection ratios are now available that make EEG recording more possible and less susceptible to noise and other artifacts. We have seen that excellent quality EEGs are now possible for even extremely preterm infants in the NICU, as long as there is adequate setup and preparation (85). Multiple channels of EEG are not required to assess the grade of EEG baseline activity in the DR, one channel of good quality EEG is perfectly acceptable to assess amplitude, continuity, and

\section{REFERENCES}

1. Bonifacio SL, Glass HC, Peloquin S, Ferriero DM. A new neurological focus in neonatal intensive care. Nat Rev Neurol (2011) 7(9):485-94. doi:10.1038/ nrneurol.2011.119

2. Chang T, Tsuchida TN. Conventional (continuous) EEG monitoring in the NICU. Curr Pediatr Rev (2014) 10(1):2-10. doi:10.2174/1573396310011404 08115626

3. Weeke LC, Boylan GB, Pressler RM, Hallberg B, Blennow M, Toet MC, et al. Role of EEG background activity, seizure burden and MRI in predicting neurodevelopmental outcome in full-term infants with hypoxic-ischaemic encephalopathy in the era of therapeutic hypothermia. Eur J Paediatr Neurol (2016) 20(6):855-64. doi:10.1016/j.ejpn.2016.06.003

4. Lamblin MD, Esquivel EW, Andre M. The electroencephalogram of the full-term newborn: review of normal features and hypoxic-ischemic encephalopathy patterns. Neurophysiol Clin (2013) 43(5-6):267-87. doi:10.1016/j. neucli.2013.07.001 frequency of the EEG. EEG sensors are constantly evolving, and newer disposable single application sensors are now available also making EEG electrode acquisition more feasible.

Electroencephalography has long been considered just too difficult to deploy in environments like the DR and NICU. There have been major recent advances to the adoption of EEG in the NICU primarily due to advances in technology (2). Modern machine learning techniques are also advancing rapidly and will soon be able to provide non-EEG experts with the help needed to assist in the interpretation of EEG patterns on a 24/7/365 basis. These difficulties should no longer be a barrier to the adoption of EEG in the DR.

In conclusion, the time is now right to advance the objective monitoring of neurological function of newborn infants in the $\mathrm{DR}$, and urgent research is clearly warranted. More EEG studies from healthy term and preterm newborns in the DR to establish feasibility and normative reference ranges are clearly a priority. Advances in automated analysis of the baseline EEG will be hugely beneficial in this effort particularly if outputs are incorporated into standard patient monitors. We look forward to further studies in this area.

\section{AUTHOR CONTRIBUTIONS}

GB and ED conceived and designed the review. DF performed the literature search and drafted the initial manuscript. All the authors (DF, ED, and GB) critically revised the manuscript for important intellectual content, agreed on the final manuscript, and approved its submission for publication.

\section{FUNDING}

This research was funded by a Science Foundation Ireland Research Centre Award (INFANT-12/RC/2272).

\section{SUPPLEMENTARY MATERIAL}

The Supplementary Material for this article can be found online at http://journal.frontiersin.org/article/10.3389/fped.2017.00173/ full\#supplementary-material.

5. Pressler RM, Boylan GB, Morton M, Binnie CD, Rennie JM. Early serial EEG in hypoxic ischaemic encephalopathy. Clin Neurophysiol (2001) 112(1):31-7. doi:10.1016/S1388-2457(00)00517-4

6. Toet MC, Lemmers PM. Brain monitoring in neonates. Early Hum Dev (2009) 85(2):77-84. doi:10.1016/j.earlhumdev.2008.11.007

7. Boylan GB, Kharoshankaya L, Wusthoff CJ. Seizures and hypothermia: importance of electroencephalographic monitoring and considerations for treatment. Semin Fetal Neonatal Med (2015) 20(2):103-8. doi:10.1016/j.siny.2015.01.001

8. Glass HC, Wusthoff CJ, Shellhaas RA, Tsuchida TN, Bonifacio SL, Cordeiro M, et al. Risk factors for EEG seizures in neonates treated with hypothermia: a multicenter cohort study. Neurology (2014) 82(14):1239-44. doi:10.1212/ WNL.0000000000000282

9. Boylan GB, Stevenson NJ, Vanhatalo S. Monitoring neonatal seizures. Semin Fetal Neonatal Med (2013) 18(4):202-8. doi:10.1016/j.siny.2013.04.004

10. Lloyd RO, O’Toole JM, Pavlidis E, Filan PM, Boylan GB. Electrographic seizures during the early postnatal period in preterm infants. J Pediatr (2017) 187:18-25 e2. doi:10.1016/j.jpeds.2017.03.004 
11. Shah DK, Mackay MT, Lavery S, Watson S, Harvey AS, Zempel J, et al. Accuracy of bedside electroencephalographic monitoring in comparison with simultaneous continuous conventional electroencephalography for seizure detection in term infants. Pediatrics (2008) 121(6):1146-54. doi:10.1542/ peds.2007-1839

12. Evans E, Koh S, Lerner J, Sankar R, Garg M. Accuracy of amplitude integrated EEG in a neonatal cohort. Arch Dis Child Fetal Neonatal Ed (2010) 95(3):F169-73. doi:10.1136/adc.2009.165969

13. de Vries LS, Toet MC. Amplitude integrated electroencephalography in the full-term newborn. Clin Perinatol (2006) 33(3):619-32, vi. doi:10.1016/j. clp.2006.06.002

14. Murray DM, O'Connor CM, Ryan CA, Korotchikova I, Boylan GB. Early EEG grade and outcome at 5 years after mild neonatal hypoxic ischemic encephalopathy. Pediatrics (2016) 138(4):e20160659. doi:10.1542/peds. 2016-0659

15. Murray DM, Boylan GB, Ryan CA, Connolly S. Early EEG findings in hypoxic-ischemic encephalopathy predict outcomes at 2 years. Pediatrics (2009) 124(3):e459-67. doi:10.1542/peds.2008-2190

16. Perivier M, Roze JC, Gascoin G, Hanf M, Branger B, Rouger V, et al. Neonatal EEG and neurodevelopmental outcome in preterm infants born before 32 weeks. Arch Dis Child Fetal Neonatal Ed (2015) 101(3):F253-9. doi:10.1136/ archdischild-2015-308664

17. Tsuchida TN. EEG background patterns and prognostication of neonatal encephalopathy in the era of hypothermia. JClin Neurophysiol (2013) 30(2):122-5. doi:10.1097/WNP.0b013e3182872ac2

18. Le Bihannic A, Beauvais K, Busnel A, de Barace C, Furby A. Prognostic value of EEG in very premature newborns. Arch Dis Child Fetal Neonatal Ed (2012) 97(2):F106-9. doi:10.1136/adc.2010.204735

19. Wikstrom S, Pupp IH, Rosen I, Norman E, Fellman V, Ley D, et al. Early single-channel aEEG/EEG predicts outcome in very preterm infants. Acta Paediatr (2012) 101(7):719-26. doi:10.1111/j.1651-2227.2012.02677.x

20. Fogtmann EP, Plomgaard AM, Greisen G, Gluud C. Prognostic accuracy of electroencephalograms in preterm infants: a systematic review. Pediatrics (2017) 139(2):e20161951. doi:10.1542/peds.2016-1951

21. Lloyd RO, O'Toole JM, Livingstone V, Hutch WD, Pavlidis E, Cronin AM, et al. Predicting 2-y outcome in preterm infants using early multimodal physiological monitoring. Pediatr Res (2016) 80(3):382-8. doi:10.1038/pr.2016.92

22. Kleinman ME, Chameides L, Schexnayder SM, Samson RA, Hazinski MF, Atkins DL, et al. Pediatric advanced life support: 2010 American Heart Association guidelines for cardiopulmonary resuscitation and emergency cardiovascular care. Pediatrics (2010) 126(5):e1361-99. doi:10.1542/peds. 2010-2972D

23. Fanaroff AA, Stoll BJ, Wright LL, Carlo WA, Ehrenkranz RA, Stark AR, et al. Trends in neonatal morbidity and mortality for very low birthweight infants. Am J Obstet Gynecol (2007) 196(2):147.e1-8. doi:10.1016/j.ajog.2006.09.014

24. Liu L, Johnson HL, Cousens S, Perin J, Scott S, Lawn JE, et al. Global, regional, and national causes of child mortality: an updated systematic analysis for 2010 with time trends since 2000. Lancet (2012) 379(9832):2151-61. doi:10.1016/ S0140-6736(12)60560-1

25. Perlman JM, Wyllie J, Kattwinkel J, Wyckoff MH, Aziz K, Guinsburg R, et al. Part 7: neonatal resuscitation: 2015 international consensus on cardiopulmonary resuscitation and emergency cardiovascular care science with treatment recommendations (reprint). Pediatrics (2015) 136(Suppl 2):S120-66. doi:10.1542/ peds.2015-3373D

26. Wyllie J, Bruinenberg J, Roehr CC, Rudiger M, Trevisanuto D, Urlesberger B. European Resuscitation Council guidelines for resuscitation 2015: section 7. Resuscitation and support of transition of babies at birth. Resuscitation (2015) 95:249-63. doi:10.1016/j.resuscitation.2015.07.029

27. Apgar V.A proposal for a new method of evaluation of the newborn infant. Curr Res Anesth Analg(1953)32(4):260-7.doi:10.1213/00000539-195301000-00041

28. Casey BM, McIntire DD, Leveno KJ. The continuing value of the Apgar score for the assessment of newborn infants. N Engl J Med (2001) 344(7):467-71. doi:10.1056/NEJM200102153440701

29. O'Donnell CP, Kamlin CO, Davis PG, Carlin JB, Morley CJ. Interobserver variability of the 5-minute Apgar score. JPediatr (2006) 149(4):486-9. doi:10.1016/j.jpeds.2006.05.040

30. Dawson JA, Kamlin CO, Vento M, Wong C, Cole TJ, Donath SM, et al. Defining the reference range for oxygen saturation for infants after birth. Pediatrics (2010) 125(6):e1340-7. doi:10.1542/peds.2009-1510
31. Dawson JA, Kamlin CO, Wong C, te Pas AB, Vento M, Cole TJ, et al. Changes in heart rate in the first minutes after birth. Arch Dis Child Fetal Neonatal Ed (2010) 95(3):F177-81. doi:10.1136/adc.2009.169102

32. Dawson JA, Morley CJ. Monitoring oxygen saturation and heart rate in the early neonatal period. Semin Fetal Neonatal Med (2010) 15(4):203-7. doi:10.1016/j.siny.2010.03.004

33. Sonesson SE, Winberg P, Lundell BP. Early postnatal changes in intracranial arterial blood flow velocities in term infants. Pediatr Res (1987) 22(4):461-4. doi:10.1203/00006450-198710000-00020

34. Maesel A, Sladkevicius P, Gudmundsson S, Mars al K. Mode of delivery and perinatal cerebral blood flow. Early Hum Dev (1996) 44(3):179-85. doi:10.1016/0378-3782(95)01707-0

35. Maesel A, Sladkevicius P, Valentin L, Marsal K. Fetal cerebral blood flow velocity during labor and the early neonatal period. Ultrasound Obstet Gynecol (1994) 4(5):372-6. doi:10.1046/j.1469-0705.1994.04050372.x

36. Ipsiroglu OS, Stockler S, Hausler MC, Kainer F, Rosegger H, Weiss PA, et al. Cerebral blood flow velocities in the first minutes of life. Eur J Pediatr (1993) 152(3):269-70. doi:10.1007/BF01956162

37. Noori S, Wlodaver A, Gottipati V, McCoy M, Schultz D, Escobedo M. Transitional changes in cardiac and cerebral hemodynamics in term neonates at birth. J Pediatr (2012) 160(6):943-8. doi:10.1016/j.jpeds.2011.12.008

38. Jorch G, Rabe H, Michel E, Engels M, Schulz V, Hentschel R, et al. Resuscitation of the very immature infant: cerebral Doppler flow velocities in the first 20 minutes of life. Biol Neonate (1993) 64(4):215-20. doi:10.1159/000243992

39. Fauchere JC, Schulz G, Haensse D, Keller E, Ersch J, Bucher HU, et al. Nearinfrared spectroscopy measurements of cerebral oxygenation in newborns during immediate postnatal adaptation. J Pediatr (2010) 156(3):372-6. doi:10.1016/j.jpeds.2009.09.050

40. Binder C, Urlesberger B, Avian A, Pocivalnik M, Muller W, Pichler G. Cerebral and peripheral regional oxygen saturation during postnatal transition in preterm neonates. J Pediatr (2013) 163(2):394-9. doi:10.1016/j. jpeds.2013.01.026

41. Kratky E, Pichler G, Rehak T, Avian A, Pocivalnik M, Muller W, et al. Regional cerebral oxygen saturation in newborn infants in the first 15 min of life after vaginal delivery. Physiol Meas (2012) 33(1):95-102. doi:10.1088/0967-3334/33/1/95

42. Pichler G, Binder C, Avian A, Beckenbach E, Schmolzer GM, Urlesberger B. Reference ranges for regional cerebral tissue oxygen saturation and fractional oxygen extraction in neonates during immediate transition after birth. J Pediatr (2013) 163(6):1558-63. doi:10.1016/j.jpeds.2013.07.007

43. Urlesberger B, Grossauer K, Pocivalnik M, Avian A, Muller W, Pichler G. Regional oxygen saturation of the brain and peripheral tissue during birth transition of term infants. J Pediatr (2010) 157(5):740-4. doi:10.1016/j. jpeds.2010.05.013

44. Urlesberger B, Kratky E, Rehak T, Pocivalnik M, Avian A, Czihak J, et al. Regional oxygen saturation of the brain during birth transition of term infants: comparison between elective cesarean and vaginal deliveries. J Pediatr (2011) 159(3):404-8. doi:10.1016/j.jpeds.2011.02.030

45. Almaazmi M, Schmid MB, Havers S, Reister F, Lindner W, Mayer B, et al. Cerebral near-infrared spectroscopy during transition of healthy term newborns. Neonatology (2013) 103(4):246-51. doi:10.1159/000345926

46. Fuchs H, Lindner W, Buschko A, Almazam M, Hummler HD, Schmid MB. Brain oxygenation monitoring during neonatal resuscitation of very low birth weight infants. J Perinatol (2012) 32(5):356-62. doi:10.1038/jp. 2011.110

47. Frasch MG, Keen AE, Gagnon R, Ross MG, Richardson BS. Monitoring fetal electrocortical activity during labour for predicting worsening acidemia: a prospective study in the ovine fetus near term. PLoS One (2011) 6(7):e22100. doi:10.1371/journal.pone.0022100

48. Frasch MG, Durosier LD, Gold N, Cao M, Matushewski B, Keenliside L, et al. Adaptive shut-down of EEG activity predicts critical acidemia in the nearterm ovine fetus. Physiol Rep (2015) 3(7):e12435. doi:10.14814/phy2.12435

49. Wang X, Durosier LD, Ross MG, Richardson BS, Frasch MG. Online detection of fetal acidemia during labour by testing synchronization of EEG and heart rate: a prospective study in fetal sheep. PLoS One (2014) 9(9):e108119. doi:10.1371/journal.pone.0108119

50. Thaler I, Boldes R, Timor-Tritsch I. Real-time spectral analysis of the fetal EEG: a new approach to monitoring sleep states and fetal condition during labor. Pediatr Res (2000) 48(3):340-5. doi:10.1203/00006450-200009000-00013 
51. Lear CA, Galinsky R, Wassink G, Yamaguchi K, Davidson JO, Westgate JA, et al. The myths and physiology surrounding intrapartum decelerations: the critical role of the peripheral chemoreflex. J Physiol (2016) 594(17):4711-25. doi:10.1113/JP271205

52. Gunn AJ, Parer JT, Mallard EC, Williams CE, Gluckman PD. Cerebral histologic and electrocorticographic changes after asphyxia in fetal sheep. Pediatr Res (1992) 31(5):486-91. doi:10.1203/00006450-199205000-00016

53. Low E, Dempsey EM, Ryan CA, Rennie JM, Boylan GB. EEG suppression associated with apneic episodes in a neonate. Case Rep Neurol Med (2012) 2012:250801. doi:10.1155/2012/250801

54. Hunter CJ, Bennet L, Power GG, Roelfsema V, Blood AB, Quaedackers JS, et al. Key neuroprotective role for endogenous adenosine A1 receptor activation during asphyxia in the fetal sheep. Stroke (2003) 34(9):2240-5. doi:10.1161/01. STR.0000083623.77327.CE

55. Benda GI, Engel RC, Zhang YP. Prolonged inactive phases during the discontinuous pattern of prematurity in the electroencephalogram of very-low-birthweight infants. Electroencephalogr Clin Neurophysiol (1989) 72(3):189-97. doi:10.1016/0013-4694(89)90243-5

56. Hellstrom-Westas L, Rosen I, Svenningsen NW. Predictive value of early continuous amplitude integrated EEG recordings on outcome after severe birth asphyxia in full term infants. Arch Dis Child Fetal Neonatal Ed (1995) 72(1):F34-8. doi:10.1136/fn.72.1.F34

57. Thoresen M, Tooley J, Liu X, Jary S, Fleming P, Luyt K, et al. Time is brain: starting therapeutic hypothermia within three hours after birth improves motor outcome in asphyxiated newborns. Neonatology (2013) 104(3):228-33. doi:10.1159/000353948

58. Liberati A, Altman DG, Tetzlaff J, Mulrow C, Gotzsche PC, Ioannidis JP, et al. The PRISMA statement for reporting systematic reviews and meta-analyses of studies that evaluate health care interventions: explanation and elaboration. J Clin Epidemiol (2009) 62(10):e1-34. doi:10.1016/j.jclinepi.2009. 06.006

59. Pichler G, Cheung PY, Aziz K, Urlesberger B, Schmolzer GM. How to monitor the brain during immediate neonatal transition and resuscitation? A systematic qualitative review of the literature. Neonatology (2014) 105(3):205-10. doi:10.1159/000357162

60. Pichler G, Avian A, Binder C, Zotter H, Schmolzer GM, Morris N, et al. aEEG and NIRS during transition and resuscitation after birth: promising additional tools; an observational study. Resuscitation (2013) 84(7):974-8. doi:10.1016/j. resuscitation.2012.12.025

61. Tamussino A, Urlesberger B, Baik N, Schwaberger B, Binder-Heschl C, Schmolzer GM, et al. Low cerebral activity and cerebral oxygenation during immediate transition in term neonates - a prospective observational study. Resuscitation (2016) 103:49-53. doi:10.1016/j.resuscitation.2016.03.011

62. Wang L, Zhang W, Zhao Y. The study of maternal and fetal plasma catecholamines levels during pregnancy and delivery. JPerinat Med (1999) 27(3):195-8. doi:10.1515/JPM.1999.027

63. Menke J, Voss U, Moller G, Jorch G. Reproducibility of cerebral near infrared spectroscopy in neonates. Biol Neonate (2003) 83(1):6-11. doi:10.1159/000067006

64. Spitzmiller RE, Phillips T, Meinzen-Derr J, Hoath SB. Amplitude-integrated EEG is useful in predicting neurodevelopmental outcome in full-term infants with hypoxic-ischemic encephalopathy: a meta-analysis. J Child Neurol (2007) 22(9):1069-78. doi:10.1177/0883073807306258

65. Thoresen M, Hellstrom-Westas L, Liu X, de Vries LS. Effect of hypothermia on amplitude-integrated electroencephalogram in infants with asphyxia. Pediatrics (2010) 126(1):e131-9. doi:10.1542/peds.2009-2938

66. Hellstrom-Westas L, Klette H, Thorngren-Jerneck K, Rosen I. Early prediction of outcome with aEEG in preterm infants with large intraventricular hemorrhages. Neuropediatrics (2001) 32(6):319-24. doi:10.1055/s-2001-20408

67. Pavlidis E, Lloyd RO, Boylan GB. EEG - a valuable biomarker of brain injury in preterm infants. Dev Neurosci (2017) 39(1-4):23-35. doi:10.1159/000456659

68. Iyer KK, Roberts JA, Hellstrom-Westas L, Wikstrom S, Hansen Pupp I, Ley D, et al. Early detection of preterm intraventricular hemorrhage from clinical electroencephalography. Crit Care Med (2015) 43(10):2219-27. doi:10.1097/CCM.0000000000001190

69. Palmu K, Wikstrom S, Hippelainen E, Boylan G, Hellstrom-Westas L, Vanhatalo S. Detection of 'EEG bursts' in the early preterm EEG: visual vs. automated detection. Clin Neurophysiol (2010) 121(7):1015-22. doi:10.1016/j. clinph.2010.02.010
70. O’Toole JM, Boylan GB, Vanhatalo S, Stevenson NJ. Estimating functiona brain maturity in very and extremely preterm neonates using automated analysis of the electroencephalogram. Clin Neurophysiol (2016) 127(8):2910-8. doi:10.1016/j.clinph.2016.02.024

71. Zhang D, Ding H. Calculation of compact amplitude-integrated EEG tracing and upper and lower margins using raw EEG data. Health (NY) (2013) 5(5):85-891. doi:10.4236/health.2013.55116

72. Niemarkt H, Andriessen P, Halbertsma FJ. Artefacts in the amplitude-integrated EEG background pattern of a full-term asphyxiated neonate caused by diaphragm spasms. BMJ Case Rep (2012) 2012:bcr1220115363. doi:10.1136/ bcr.12.2011.5363

73. Marics G, Cseko A, Vasarhelyi B, Zakarias D, Schuster G, Szabo M. Prevalence and etiology of false normal aEEG recordings in neonatal hypoxic-ischaemic encephalopathy. BMC Pediatr (2013) 13:194. doi:10.1186/1471-2431-13-194

74. ter Horst HJ, Sommer C, Bergman KA, Fock JM, van Weerden TW, Bos AF. Prognostic significance of amplitude-integrated EEG during the first 72 hours after birth in severely asphyxiated neonates. Pediatr Res (2004) 55(6):1026-33. doi:10.1203/01.pdr.0000127019.52562.8c

75. van Rooij LG, Toet MC, Osredkar D, van Huffelen AC, Groenendaal F, de Vries LS. Recovery of amplitude integrated electroencephalographic background patterns within 24 hours of perinatal asphyxia. Arch Dis Child Fetal Neonatal Ed (2005) 90(3):F245-51. doi:10.1136/adc.2004.064964

76. Keogh MJ, Drury PP, Bennet L, Davidson JO, Mathai S, Gunn ER, et al. Limited predictive value of early changes in EEG spectral power for neural injury after asphyxia in preterm fetal sheep. Pediatr Res (2012) 71(4 Pt 1):345-53. doi:10.1038/pr.2011.80

77. Hirst JJ, Palliser HK, Yates DM, Yawno T, Walker DW. Neurosteroids in the fetus and neonate: potential protective role in compromised pregnancies. Neurochem Int (2008) 52(4-5):602-10. doi:10.1016/j.neuint.2007.07.018

78. Nguyen PN, Yan EB, Castillo-Melendez M, Walker DW, Hirst JJ. Increased allopregnanolone levels in the fetal sheep brain following umbilical cord occlusion. J Physiol (2004) 560(Pt 2):593-602. doi:10.1113/jphysiol.2004.069336

79. Murphy K, Stevenson NJ, Goulding RM, Lloyd RO, Korotchikova I, Livingstone V, et al. Automated analysis of multi-channel EEG in preterm infants. Clin Neurophysiol (2015) 126(9):1692-702. doi:10.1016/j.clinph.2014. 11.024

80. Matic V, Cherian PJ, Koolen N, Ansari AH, Naulaers G, Govaert P, et al. Objective differentiation of neonatal EEG background grades using detrended fluctuation analysis. Front Hum Neurosci (2015) 9:189. doi:10.3389/ fnhum.2015.00189

81. Koolen N, Oberdorfer L, Rona Z, Giordano V, Werther T, KlebermassSchrehof K, et al. Automated classification of neonatal sleep states using EEG. Clin Neurophysiol (2017) 128(6):1100-8. doi:10.1016/j.clinph.2017.02.025

82. Dunne JM, Wertheim D, Clarke P, Kapellou O, Chisholm P, Boardman JP, et al. Automated electroencephalographic discontinuity in cooled newborns predicts cerebral MRI and neurodevelopmental outcome. Arch Dis Child Fetal Neonatal Ed (2017) 102(1):F58-64. doi:10.1136/archdischild-2015-309697

83. Ahmed R, Temko A, Marnane W, Lightbody G, Boylan G. Grading hypoxic-ischemic encephalopathy severity in neonatal EEG using GMM supervectors and the support vector machine. Clin Neurophysiol (2016) 127(1):297-309. doi:10.1016/j.clinph.2015.05.024

84. Stevenson NJ, Korotchikova I, Temko A, Lightbody G, Marnane WP, Boylan GB. An automated system for grading EEG abnormality in term neonates with hypoxic-ischaemic encephalopathy. Ann Biomed Eng (2013) 41(4):775-85. doi:10.1007/s10439-012-0710-5

85. Lloyd R, Goulding R, Filan P, Boylan G. Overcoming the practical challenges of electroencephalography for very preterm infants in the neonatal intensive care unit. Acta Paediatr (2015) 104(2):152-7. doi:10.1111/apa.12869

Conflict of Interest Statement: The authors declare that the research was conducted in the absence of any commercial or financial relationships that could be construed as a potential conflict of interest.

Copyright (c) 2017 Finn, Dempsey and Boylan. This is an open-access article distributed under the terms of the Creative Commons Attribution License (CC BY). The use, distribution or reproduction in other forums is permitted, provided the original author(s) or licensor are credited and that the original publication in this journal is cited, in accordance with accepted academic practice. No use, distribution or reproduction is permitted which does not comply with these terms. 